\title{
Um estudo metapsicológico sobre o conceito de pulsão de morte e sua articulação com a repetição
}

\author{
A metapsychological study on the concept of pulsion of death and its articulation with repetition
}

\author{
Kamilla Mariano dos Santos Barbosa ${ }^{\dagger *}$, Fernanda Cabral Samico
}

Como citar esse artigo. Barbosa,

K.M.S.; Samico, F.C. Um estudo metapsicológico sobre o conceito de pulsão de morte e sua articulação com a repetição. Revista Mosaico $2019 \mathrm{Jul} /$. Dez.; 10 (2): SUPLEMENTO 48-54

\begin{abstract}
Resumo
O tema abordado no presente estudo refere-se aos conceitos de pulsão de morte, compulsão à repetição e às questões latentes, a saber, as que são encobertas pelo recalque e, portanto desconhecidas ao sujeito. O fator a ser analisado é "como uma repetição da vivência de dor do trauma, o que era até o momento, um motivo de aversão, torna-se um pólo atrativo?’. O artigo utilizou da metodologia de revisão bibliográfica, a partir das obras de Freud e seus comentadores. Para abordar a pulsão de morte, fezse necessário refazer um breve percurso em torno do conceito teórico de pulsão. A partir disso, pudemos expor seu aspecto repetitivo e finalmente nos debruçamos sobre o conceito central de nossa pesquisa, a saber, a compulsão à repetição. Somente a partir daí foi possível elaborar um escrita sobre a repetição da experiência de dor relacionada ao traumático e sua função.

Palavras-chave: Pulsão de morte, psicanálise, repetição, trauma.
\end{abstract}

\section{Introdução}

A pulsão de morte é um dos conceitos mais controversos e ao mesmo tempo um dos mais interessantes da metapsicologia psicanalítica. Historicamente, tal conceito freudiano gerou grande polêmica e não foi aceito por alguns psicanalistas. Contudo, trata-se de um conceito que está no âmago da psicanálise e revela uma dimensão que reside no cerne do aparelho psíquico. Segundo Roudinesco e Plon (1998), essa teoria provocou grande repercussão e rejeição na psicanálise, com argumentações sobre a falta de embasamento empírico para a existência de uma pulsão de morte. Alguns teóricos investigaram a fundo sobre este conceito apresentando algumas reformulações ou acréscimos, como é o caso de Jean Laplanche, André
Green, Melanie Klein e outros que não aderiram a esta ideia freudiana,como é o caso de Winnicott.

Lacan, em seu retorno à obra freudiana, ao teorizar sobre a pulsão, diz que seu primeiro dado "[...] é que ela não tem dia nem noite, não tem primavera nem outono, não tem subida, nem descida. É uma força constante" (LACAN apud JORGE, 2008, p.47). Esse caráter de força da pulsão age através de uma energia chamada libido. É uma energia que jamais decresce, pois está sempre no patamar de intensidade. Todavia, precisa-se diferenciar o fator econômico, que se refere à intensidade da pulsão do fator dinâmico, que remete à descarga pulsional e topográfico, que diz respeito às inscrições psíquicas (PAIM FILHO, 2010, p.118).

A respeito à repetição, o conceito está relacionado à ideia de retorno, reprodução de algo idêntico, repetir determinada ação (PAIM FILHO, 2010, p.118). Assim,

Afiliação dos autores: $\uparrow$ Graduanda. Curso de Psicologia. Universidade de Vassouras. RJ. Brasil

* Doutora em Psicanálise. Professora do Curso de Psicologia. Universidade Vassouras, RJ, Brasil.

* Email de correspondencia: ka_milla.16@hotmail.com 
a compulsão à repetição não possibilitaria o surgimento de um campo para o novo, ou seja, não abriria espaço para novos caminhos que a pulsão pudesse percorrer. Assim sendo, abordamos nesse artigo como a pulsão de morte está relacionada ao conceito de compulsão à repetição e de que maneira este conceito serve à perpetuação do sofrimento psíquico. Compulsão é um conceito energético, refere-se à força da pulsão. Se seguirmos a ideia proposta por Paim Filho (2010) e decompusermos a palavra compulsão, teremos o prefixo "com", que significa "somar" e, quanto ao nome "pulsão", que é puramente intensidade, não tem nenhuma qualidade, pois simplesmente está em busca de uma descarga. Ao definir este conceito a partir dessa proposta, estamos ancoradas na conceituação freudiana que afirma "a pulsão como sendo o conceito fronteira entre o somático e o psíquico" (FREUD, 1911/1969, p. 99). Dessa forma, de maneira mais sucinta, podemos afirmar que a compulsão é uma faceta da pulsão com um nível maior intensidade e a apresentação de um dado econômico, ou seja, um acúmulo energético. A compulsão, quando é investida numa inscrição psíquica, propõe um caminho a seguir, os destinos que levam à repetição.

Nossa proposta foi a de conduzir essas articulações teóricas, para que possam ser problematizadas e ampliadas, considerando-se a oposição entre pulsão de vida (Eros) e pulsão de morte. Em Freud (1920/1996), Eros é compatível com a ligação, ou seja, com a capacidade de investimento libidinal nos objetos escolhidos pelo sujeito no decorrer de sua vida; enquanto que na via oposta, a pulsão de morte se caracteriza pelo desinvestimento, pelo desligamento. É por esta possibilidade de se entender o investimento e desinvestimento objetal sob a ótica da segunda teoria das pulsões que pretendemos articulá-las à repetição como sintoma decorrente do além do princípio prazer, centrado no poder do traumático. Dessa forma, em relação à repetição do além do princípio do prazer, pensamos na pulsão de morte que não é investida da pulsão sexual. Temos desta maneira, a força da pulsão de morte impossibilitada de proporcionar novos campos, e o destino que lhe resta é continuar retornando a uma questão latente.

\section{A origem das pulsões}

Na obra Três ensaios sobre a teoria da sexualidade (1905/1996), Freud apresenta a pulsão e neste escrito, este conceito é colocado como o representante psíquico de uma energia que leva ao movimento ou a uma determinada demanda por ação ao psiquismo, cuja fonte seria o processo excitatório de um órgão. Dessa forma, identifica-se uma distinção entre a fonte da pulsão e o estímulo, sendo este último produzido fora do organismo e a fonte da pulsão dentro do organismo. Esta pulsão, diferentemente do estímulo, não poderia ser descartada, sendo, pois contínua e conservadora. Para Freud, há algo na própria natureza da pulsão que parece fadá-la à insatisfação, havendo sempre uma diferença constante entre a satisfação almejada e aquela obtida. Ainda nesse texto, Freud (1905/1996) diz que todas as pulsões direcionavam-se ao movimento e destaca a pulsão sexual, atribuindo à sua energia o nome de libido. Neste mesmo trabalho, também menciona "pulsões de fome", relacionadas à necessidade de nutrição e protótipo da pulsão de autoconservação, que aparecerá em 1910.

Segundo Jorge (2008, p.21), a teoria freudiana das pulsões, surgida a partir de experiências clínicas de escuta dos pacientes neuróticos em análise, é resultado da ocorrência universal de uma sexualidade que se manifesta sob uma lógica diferente daquela que rege os instintos dos animais. Em relação à diferenciação entre pulsão e instinto, o elemento central da teoria freudiana da pulsão é a sua natureza eminentemente parcial, caracterizado por uma fonte pulsional e por um alvo, que significa a resolução de uma tensão interna. Através da formulação da parcialidade da pulsão, Freud indica o erro inerente ao fato de se restringir a sexualidade humana ao aspecto da reprodução (JORGE, 2008).

Sobre as pulsões parciais, de acordo com Três ensaios sobre a teoria da sexualidade (1905/1996), Freud destaca não somente a vigência de uma sexualidade infantil, mas também indica nesta uma estrutura perverso-polimorfa, originária para o ser humano, apontando que o conceito de pulsão se situa entre o somático e o psíquico e propõe as fases do desenvolvimento da libido, na qual demarca as zonas erógenas. Tal processo não se restringe a apenas uma região corporal específica, mas estende-se por todo o corpo do sujeito, transformando-o assim, em um corpo erógeno, ou podemos dizer, em um corpo pulsional. Embora estejam ligadas à sexualidade infantil, as pulsões parciais não são abandonadas durante a puberdade. Essas pulsões funcionam mais tarde sob a forma dos prazeres preliminares e nas perversões. Apesar de no período da puberdade, a sexualidade ter uma forma de organização, as pulsões parciais ainda se encontram ativas, mesmo que sob o destino do recalque.

Antes mesmo de teorizar sobre o primeiro dualismo pulsional, Freud mostrava que essa teoria seria mantida até aparecerem novas evidências, como podemos ver na seguinte afirmação:

Propusquesedistingamdoisgruposdetaispulsõesprimordiais: as pulsões do ego, ou autopreservativas, e as pulsões sexuais. Mas essa suposição não tem status de postulado necessário, ela não passa de uma hipótese de trabalho, a ser conservada apenas enquanto se mostrar útil, e pouca diferença fará aos resultados do nosso trabalho de descrição e classificação se for substituída por outra. (FREUD, 1905/1996, p. 139) 
Mais tarde, no texto A concepção psicanalítica da perturbação psicogênica da visão (1910/1969), Freud enuncia seu primeiro dualismo pulsional, com a introdução do conceito pulsão do ego. $\mathrm{O}$ conflito psíquico se faria entre a pulsão sexual, a serviço da sexualidade e a pulsão do ego, a serviço da conservação do indivíduo.

A teoria pulsional é um dos estudos metapsicológicos mais essenciais da obra Freudiana. Apresentaremos a seguir os dois dualismos pulsionais e a partir daí, o desenvolvimento da pulsão de morte no decorrer de sua obra.

\section{O desenvolvimento do primeiro dualismo pulsional}

Ao teorizar seu primeiro dualismo pulsional, Freud (1910/1969) fez uma distinção entre pulsões sexuais e pulsões do ego, mais precisamente em A concepção psicanalítica da perturbação psicogênica da visão. Segundo Garcia Roza (2009), ele afirma nesse texto, que do ponto de vista da explicação psicanalítica dos fenômenos psíquicos

uma parte extremamente importante é desempenhada pela inegável oposição entre as pulsões que favorecem a sexualidade, a consecução da satisfação sexual, e as demais pulsões que têm por objetivo a autopreservação do indivíduo: as pulsões do ego. (FREUD, 1910/1969, p.199)

Nesse texto, Freud apresenta como as pulsões sexuais e as pulsões do ego se apropriam dos mesmos órgãos. Ele se utiliza do exemplo da boca que pode ter tanto a função de comer e falar e com isso estaria servindo à pulsão de autopreservação, como também pode ter a função de beijar e, nesse caso, estaria a serviço da pulsão sexual. Assim, o ego é ameaçado pelas exigências das pulsões sexuais e as desvia através de repressões; estas, todavia, não sempre produzem um resultado esperado, mas levam à formação de substitutos perigosos para o reprimido e ameaçam a integridade do ego. Freud percebe que essas duas classes de fenômenos, tomadas como um todo, formam o que chamamos de sintomas da neurose.

Em outro texto, mais dedicado à uma metapsicologia das pulsões, precisamente As pulsões e suas vicissitudes, Freud (1915/2006) ensina sobre os diferentes caminhos que uma pulsão pode percorrer, sendo que a mesma sempre terá uma força constante. Freud diz que

[...] até mesmo a atividade do aparelho mental mais desenvolvido está sujeito ao princípio de prazer, isto é, que ela é automaticamente regulada por sentimentos pertencentes à série prazer-desprazer. É necessário preservar com cuidado essa ideia em sua forma indefinida, até conseguirmos, caso possível, descobrir qual o tipo de relação existe entre o prazer e o desprazer, por um lado, e flutuações nas quantidades de estímulo que afetam a vida mental, por outro (FREUD, 1915/2006, p.73).

Ainda neste texto, Freud resgata o conceito de pulsão relacionado à diferenciação entre estímulos externos e internos. Quando se apresentam ao aparelho psíquico, este utiliza mecanismos de defesa no sentido de se livrar da estimulação. Mais precisamente, os estímulos internos exigem do sistema nervoso muito mais do que os estímulos externos e só têm suas fontes internas de estimulação satisfeitas a partir de atividades complexas e interligadas, através das quais o mundo externo é modificado no sentido de promover a satisfação (FREUD, 1915/2006, p. 74).

$\mathrm{O}$ autor também reintroduz nesta obra os elementos acerca do funcionamento da pulsão. Primeiramente descreve a fonte (Quelle), que significa o processo somático que ocorre em um órgão ou parte do corpo, mas em termos de via mental, só chegamos a conhecê-lo através das finalidades pulsionais. Segundo Garcia Roza, entende-se por fonte "somática ou "fonte orgânica" tanto o órgão de onde provém a excitação como o processo físico-químico que constitui essa excitação (GARCIA ROZA, 2009, p.119).

A Finalidade ou objetivo (Ziel) corresponde à satisfação e só pode se alcançada através da eliminação do estado de estimulação, por um caminho direto ou através da combinação de várias finalidades mais próximas ou intermediárias que se combinam e se intercambiam umas com as outras no sentido de chegar à finalidade última, vale ressaltar que o objetivo da pulsão é sempre a "satisfação", este último termo refere-se à redução da tensão provocada por uma pressão (Drang);

O termo pressão (Drang) é citado por Freud pelo fato de a pulsão ser uma pressão constante; Por último, Freud define objeto (Object), onde a pulsão alcança sua finalidade. Garcia Roza (2009) diz que, inicialmente, Freud considerava o objeto como uma pessoa, isto é, algo que possuía um sentido individual e completo. Posteriormente, a ideia de objeto se aplicou tanto às outras pessoas, como à própria pessoa (isto inclui a pessoa como um todo ou determinadas partes dessa pessoa) e este objeto pode ser real ou fantasmático (GARCIA ROZA, 2009, p.122).

Lacan (apud JORGE, 2008), ao estudar a pulsão na obra de Freud, especificamente no primeiro dualismo pulsional, ressalta a impossibilidade de se considerar como da ordem do pulsional aquelas atividades reunidas por Freud sob a rubrica de autoconservadoras, na medida em que, referenciadas ao nível da necessidade do organismo biológico, apresentam objetos de satisfação invariáveis e preestabelecidos. Pode-se até dizer, ao contrário, que longe de as pulsões sexuais virem a se apoiar naquelas de autoconservação, são estas que, na verdade, se apóiam naquelas: "a especificidade do 
humano implica precisamente que o funcional seja subvertido de modo constante pelo pulsional" (JORGE, 2008, p.48). Assim, o dualismo pulsional inicial dá lugar, na teoria freudiana, a um segundo dualismo, mantido por Freud a partir desse momento.

\section{O segundo dualismo pulsional: desenvolvimento da pulsão de morte}

Freud em Além do principio do prazer (1920/1996), amplia a noção de pulsão e sistematiza a existência da pulsão de morte. Essa nova concepção de pulsão faz surgir uma nova teoria. As pulsões de vida e de morte passam a dirigir o funcionamento do aparelho psíquico. A primeira teoria pulsional, que mais tarde foi abandonada, consistia na divisão entre pulsões de ego e pulsões sexuais, relacionadas à manutenção da espécie e à conservação da integridade do sujeito. A segunda teoria pulsional foi direcionada à "descatexização", ou seja, à diminuição da excitação, sendo conceitualizada como pulsão de morte; e a busca pelo investimento e unificação, caracterizada como pulsão de vida. Esta segunda teoria é muito relevante para a psicanálise freudiana. A partir dela, houve um melhor entendimento sobre agressividade, sadismo e masoquismo, sendo também fundamental para estudos em psicopatologia, o que influenciou diversos autores contemporâneos.

Segundo Azevedo e Mello Neto (2015), Freud agrupou as pulsões sexuais e de autopreservação, definindo-as como pulsões de vida. De acordo com os autores, uma tendência que levaria à eliminação da estimulação do organismo seria a pulsão de morte, portanto, este tipo de pulsão teria como objetivo a descarga, a falta do novo. Assim, o organismo estaria sempre destinado a buscar estados anteriores. Como diria Freud: "Esses tortuosos caminhos para a morte, fielmente seguidos pelos instintos de conservação, nos apresentariam hoje, portanto, o quadro dos fenômenos da vida" (FREUD, 1920/1996, p.49).

\section{Questionamento sobre o aspecto repetitivo da pulsão de morte}

Segundo Jorge (2008), o caráter conservador das pulsões é definido através da certificação de que todas as pulsões tendem à restauração de um estado anterior de coisas. Freud afirma que a característica da pulsão de morte de restaurar um estado anterior de coisas está voltada às pulsões no geral:

Se procurar restabelecer um estado anterior constitui característica tão universal das pulsões, não podemos surpreender-nos com que tantos processos se realizem na vida mental independentemente do princípio de prazer. Essa característica seria partilhada por todas as pulsões parciais e, em seu caso, visaria a retornar mais uma vez a uma fase específica do curso do desenvolvimento.(JORGE, 2008,p.61)

Em relação à estrutura conservadora da pulsão de morte, esta consiste na tendência do retorno a um estado inorgânico. Este caráter conservador está totalmete relacionado com seu aspecto repetitivo, dessa forma, é do caráter conservador que surge a tendência da compulsão à repetição.

Freud propõe, em Além do princípio do prazer (1920/1996), um paralelo entre a pulsão de morte, assim como destacada nos diferentes eventos psíquicos, assim como o campo da biologia. Através dele, associa o objetivo da pulsão de morte ao que considera como o retorno ao mundo inorgânico.

Segundo Jorge (2008, p. 62):

[...] a ampla referência de Freud à biologia nesse trabalho foi interpretada por Lacan como uma "metáfora teórica". Assim, no seminário sobre $\mathrm{O}$ eu na teoria de Freud e na técnica da psicanálise, Lacan afirma que, ainda que Freud se expresse, quanto ao mais-além do princípio de prazer, falando da tendência para levar o animado inteiro de volta ao inanimado, isto não significa que ele esteja falando da morte dos seres vivos, mas sim da "vivência humana, do intercâmbio humano", da "intersubjetividade", pois há algo que Freud observa no homem que o coage a sair dos limites da vida. Igualmente em "Subversão do sujeito", ao criticar toda uma pseudobiologização da teoria psicanalítica, Lacan volta a afirmar que é preciso reconhecer "na metáfora do retorno ao inanimado, do qual Freud reveste todo corpo vivo, a margem para-além da vida que a linguagem assegura ao ser pelo fato de ele falar.

O que Freud constatou sobre a pulsão de morte, segundo Lacan, foi "a existência da autonomia do simbólico, da dimensão da linguagem no homem, que parasita seu ser vivo e nele introduz o registro de um mais-além da vida (JORGE, 2008, p. 62)". Segundo Freud (1920/1996, p.40), se restaurar um estado anterior de coisas estabelece uma característica universal das pulsões, não precisaremos surpreender-nos com os processos realizados na vida mental independentemente do princípio de prazer. Essa característica seria dividida por todas as pulsões componentes e, em seu caso, tendem a retornar mais uma vez a uma fase específica do curso do desenvolvimento.

A partir deste novo contexto, deparamo-nos com uma repetição de algo que jamais foi prazeroso para o sujeito. Isto diz respeito a algo novo, uma repetição da experiência de dor. Segundo o texto de Freud Além do princípio do prazer de 1920 :

O fato novo e impressionante que iremos descrever em seguida é que a compulsão à repetição também faz retornar certas experiências do passado que não incluem nenhuma possibilidade de prazer e que, de fato, em nenhum momento teriam proporcionado satisfações prazerosas, nem mesmo para as moções pulsionais recalcadas naquela ocasião do passado. (FREUD, 1920/1996, p. 145) 
Com esse trabalho, estipulou-se uma dicotomia da compulsão à repetição. De um lado, há uma repetição comandada pelo princípio do prazer, centrada na intensidade do desejo, a partir de pontos de fixação; e, de outro, há uma repetição de algo que nunca foi prazeroso, centrada no poder do traumático.

Freud (1920/1996) percebeu que, ao invés de reduzir a carga de energia, como no princípio do prazer, o psiquismo buscava o contrário, ou seja, aumentar a carga, o que gerava desprazer. Freud entendeu que a tendência em repetir conteúdos desagradáveis contradizia o princípio do prazer, mas passou a analisar que, na verdade, estaria relacionado a algo que buscava realizar um trabalho para que o princípio do prazer pudesse vir a entrar em cena.

$\mathrm{O}$ autor discute os fatos mencionados anteriormente na análise dos sonhos nas neuroses traumáticas. Freud (1920/1996) buscava compreender como os sonhos desagradáveis aumentavam carga de excitação psíquica ao invés de serem evitados. O que encontrou foi que os conteúdos traumáticos, desagradáveis, eram revividos na tentativa do psiquismo de dominar a energia relacionada a eles, buscando um equilíbrio. Conclui que os sonhos poderiam estar apenas "ajudando a executar outra tarefa, a qual deve ser realizada antes que a dominância do princípio de prazer possa começar" (FREUD, 1920/1996, p. 42).

Assim, as experiências clínicas contribuíram para que Freud compreendesse melhor o novo conceito de pulsão de morte. Um exemplo é a brincadeira infantil, neste caso, ele observou que as crianças projetavam muito de sua vivência interna na brincadeira e a repetição de um desprazer era evidente. Desta forma, Freud reconheceu a tendência do organismo de buscar a inanição. Por isso, segundo Azevedo e Mello Neto (2015), Freud reconhece esta tendência do organismo como algo mais significativo, tanto por ter percebido como algo bastante fundamental ao psiquismo, como também por tal tendência opor-se à concepção das pulsões do ego e objetais, já que estas falavam de movimento, de investimento, de catexia, enquanto aquela dizia respeito a diminuir todo o esforço com vistas a obter o equilíbrio e a ausência de excitação.

Após este percurso teórico sobre pulsão de morte, compulsão e repetição, vejamos a seguir como vai estruturar a compulsão à repetição.

\section{Pulsão de morte e compulsão à repetição: o retorno do traumático na psicanálise}

A repetição possui uma característica marcante, uma intensidade que faz com que ganhe o atributo de compulsão. Freud no texto Recordar, repetir e elaborar de 1914, mobilizado por sua clínica, centrado nas manifestações do retorno do recalcado, em especial a transferência, percebe este fenômeno, que se caracteriza pela impossibilidade de o sujeito recordar, tendo que repetir uma ação. É importante destacar que toda repetição opera como resistência e está a serviço do conteúdo recalcado, que negocia, mas nunca renuncia à busca pela satisfação do desejo, visando reviver o que foi gratificante em algum momento do passado esquecido (PAIM FILHO, 2010, p.119).

Com o advento teórico da pulsão de morte, Freud (1920/1996) pensa na compulsão à repetição, tendo ela sua origem no trauma, em impressões psíquicas precoces, decorrentes da pulsão de morte. Segundo Samico e Jorge (2018, p. 575), ele percebe que na neurose traumática ocorre uma falha na tarefa defensiva do escudo protetor do aparelho psíquico e com isso, o mesmo acaba sendo invadido por uma carga intensa de afeto, colocando, assim, o princípio de prazer (cuja função é diminuir as tensões internas do aparelho psíquico responsáveis pelo desprazer) fora de ação temporariamente. Os autores ainda comentam que o trauma emerge, dessa forma, como algo que se origina do excesso com o qual é extremamente impossível lidar. Este tipo de excesso se constitui como algo que extrapola o prazer e, assim, remete ao que Freud denominou de mais além do princípio de prazer.

Para lidar com o excesso, o neurótico encontra como solução, na maioria das vezes, a repetição. A compulsão à repetição é o resultado da estratégia de colocar em ação repetida o encontro com o real. "Trata-se de duas dimensões diferentes da repetição intimamente relacionadas: o sujeito repete porque não consegue simbolizar e repete na tentativa de simbolizar" (SAMICO E JORGE (2018, p. 575).

Ainda neste texto, Samico e Jorge (2018) afirmam que a primeira noção de repetição foi desenvolvida em "Artigos sobre técnica"(1914/1992), nesse escrito, Freud diz que aquilo que o sujeito não consegue verbalizar em análise, ele repete em ato. A segunda noção de repetição foi introduzida por Freud alguns anos depois, quando desenvolveu a noção de uma compulsão à repetição que manifesta a ação principal da pulsão de morte, que anula o princípio de prazer. Se este regula as tensões internas do aparelho psíquico, diminuindo-as a partir do princípio de constância, seu mais além tem como objetivo radicalizar essa tendência e busca zerar essas tensões. Com essa incrível descoberta, Freud relacionou este processo à pulsão de morte (SAMICO E JORGE, 2018, p. 575).

Ao mesmo tempo em que Freud encerrava o trabalho sobre O estranho de 1919, ele começa a escrever o Além do princípio do prazer de 1920. Nesse artigo, segue dando uma continuidade às suas preocupações com a compulsão à repetição e elabora modelo metapsicológico inédito para pensar a origem da compulsão à repetição, tendo ela sua origem no traumático, decorrente da pulsão de morte. Portanto, 
diante desse novo contexto, observaremos a repetição de algo que nunca foi prazeroso para o sujeito (FREUD, 1920/2006, p. 145).

Diz respeito a algo novo, uma repetição da dor, do traumático. E o que era, até o momento, um motivo de aversão, torna-se atrativo. Podemos observar isto no trecho que encontramos nesse texto de 1920:

O fato novo e impressionante que iremos descrever em seguida é que a compulsão à repetição faz retornar certas experiências do passado que não incluem nenhuma possibilidade de prazer e que, de fato, em nenhum momento teriam proporcionado satisfações prazerosas, nem mesmo para as moções pulsionais recalcadas naquela ocasião do passado. (FREUD, 1920/2006, p. 145)

Lançando um olhar para a cultura, Paim Filho faz uma analogia brilhante com o sistema prisional Brasileiro:

Nele encontramos, via de regra, sujeitos presos, restritos em sua liberdade; porém, o trabalho de transformação que deveria ser propiciado pelo agente interditor não ocorre (não há um adequado investimento libidinal). Quando se dá a liberação carcerária, normalmente nos deparamos com sujeitos que voltam a transgredir, diríamos, a repetir de forma compulsiva, encenando o desígnio mítico de que vive sobre a centelha do "eterno retorno do mesmo" (PAIM FILHO, 2010, P.121)

A vida humana pode ser esvaziada do fator desejante e tornar-se uma vida de morte, quer por um esvaziamento de toda a energia pulsional, quer por um excesso de energia pulsional que mata o sentido da vida por insistência no seu movimento repetitivo. A verdade é que, em ambos os casos, a morte da vida humana é efeito e não objetivo do movimento pulsional. Portanto, se não existe pulsão que tenha a morte por objetivo, então mais vale dar-lhe uma nova significação (BERNET, 2016, p.7).

\section{Considerações Finais}

Com este trabalho, buscamos compreender o que levou Freud a propor a teoria pulsional que abrange este conceito de pulsão de morte, e abandonar sua primeira teoria pulsional. Chegamos à conclusão de que algumas descobertas teóricas fizeram com que esta teoria fosse substituída pelo segundo dualismo.

Tendo como perspectiva a análise da teoria pulsional freudiana e o desenvolvimento da pulsão de morte articulado com a compulsão à repetição, pensamos uma forma de responder à questão central do nosso texto: "como uma repetição da vivência de dor do trauma, o que era até o momento, um motivo de aversão, torna-se um pólo atrativo?"

A pulsão de morte deve ser entendida como força pulsional não ligada. A compulsão à repetição é caracterizada como uma resistência centrada no poder do traumático. Como assinala Freud no desenvolvimento do artigo, podemos compreender que essa resistência, em termos topográficos, está a serviço do além do princípio do prazer, ou seja, da pulsão de morte. Portanto, é uma resistência do inconsciente não recalcado.

Investigarasrespostassobreacompulsãoàrepetição é perceber o compreensível e o incompreensível. Esse quadro clínico e seus desdobramentos metapsicológicos agregam teoricamente nosso conhecimento sobre a psicanálise. A repetição é pensada na sua inter-relação com a pulsão de morte versus a pulsão sexual. Não podemos deixar de considerar que pulsão de morte, antes de tudo, é caracterizada por uma força que persiste e insiste. Essa pulsão tem a fonte na soma, sua força é intensa, tem como objetivo a descarga, e não a satisfação, pois, ao contrário da pulsão sexual, não tem objeto. Portanto, é imprescindível que sigamos refletindo sobre essa problemática, desconstruindo a noção equivocada de que a pulsão de morte é a vilã dos processos psicopatológicos. A pulsão de morte, ao agir durante compulsão à repetição, forma uma possibilidade de ser escutada e ser elaborada, pois quem recorda passa a elaborar o evento traumático. Esse acontecimento viabiliza uma integração desse traumático, que se originou da repetição na dinâmica psíquica. Ocorrendo esse processo, pode ser possível simbolizar o que antes não era simbolizado pelo sujeito.

\section{Referências}

AZEVEDO, Monia Karine; NETO, Gustavo Adolfo Ramos Mello. O desenvolvimento do conceito de pulsão de morte na obra de Freud. Revista Subjetividades, v. 15, n. 1, p. 67-75, 2015.

BERNET, Rudolf. As pulsões de morte e o enigma da compulsão de repetição (Freud e Lacan). Cultura. Revista de História e Teoria das Ideias, v. 35, p. $247-264,2016$

FREUD, Sigmund. Um caso de histeria, três ensaios sobre a teoria da sexualidade e outros trabalhos (1901-1905). Edição Standard Brasileira das Obras Psicológicas Completas de Sigmund Freud. Rio de Janeiro, Imago. Vol. VII, 1996

FREUD, Sigmund. Além do Princípio de prazer, Psicologia de Grupo e outros trabalhos (1920-1922). Edição Standard Brasileira das Obras Psicológicas Completas de Sigmund Freud. Rio de Janeiro, Imago. Vol. XVIII, 1996.

FREUD, Sigmund. O Caso Schreber, Artigos Sobre Técnica e Outros Trabalhos(1911-1913). Edição Standard Brasileira das obras completas de Sigmund Freud. Rio de Janeiro, Imago. Vol. XII, 1994.

FREUD, Sigmund. A história do movimento psicanalítico, artigos sobre a metapsicologia e outros trabalhos (1914-1916). Edição Standard Brasileira das Obras Psicológicas Completas de Sigmund Freud. Rio de Janeiro, Imago. Vol. XIV, 2006.

FREUD, Sigmund. Cinco lições de psicanálise, Leonardo da Vinci e outros trabalhos (1910). Edição standard brasileira das obras psicológicas completas de Sigmund Freud. Rio de Janeiro, Imago.Vol. XI, 1969.

FREUD, Sigmund. O ego e o id e outros trabalhos (1923-1925). Edição Standard brasileira das obras psicológicas de completas de Sigmund Freud. Rio de Janeiro, Imago. Vol. XIX, 1996.

GARCIA-ROZA, Luiz Alfredo. Freud e o inconsciente. 24 ed. Rio de Janeiro: Jorge Zahar, 2009. 
JORGE, Marco Antonio Coutinho. Fundamentos da psicanálise de Freud a Lacan, v.1, 5 ed. Rio de Janeiro: Jorge Zahar, 2008.

LAPLANCHE, Jean; PONTALIS, Jean-Bertrand. Vocabulário da psicanálise, 1988.

PAIM FILHO, Ignácio Alves. Compulsão à repetição:pulsão de morte "transin-vestida" de libido. Revista Brasileira de Psicanálise, v. 44. n.3, p. 117-126, 2010 .

ROUDINESCO, E. \& PLON, M. (1998). Dicionário de psicanálise. Rio de Janeiro: Jorge Zahar. 